\title{
Preliminary study on the practice of gonad shielding during pelvic radiography
}

\author{
Seife Teferi ${ }^{*}$, Yodit Tequabo ${ }^{2}$ and Daniel Bedane ${ }^{3}$ \\ ${ }^{1}$ Department of Radiology, Addis Ababa University College of Health sciences, school of medicine, Ethiopia \\ ${ }^{2}$ Department of Radiology, Addis Ababa University College of Health sciences, school of medicine, Ethiopia \\ ${ }^{3}$ Department of Radiology, Addis Ababa University College of Health sciences, school of medicine, Ethiopia
}

\begin{abstract}
Objective: To investigate the practice and attitudes of Medical radiologic technologists (MRTs')/radiographers on the use of Gonad shielding (GS)in pediatric radiological imaging.

Methods: A questionnaire regarding MRTs' attitudes and on the use of Gonad shielding was developed based on relevant literatures and distributed to MRTs/ radiographers working in general radiography at Black Lion and St. Paul hospitals in a study period from June to August 2014. Descriptive (percentage of frequency) study was used to analyze the responses of the multiple choices. A separate questionnaire was prepared to evaluate the practice of GS in these two hospitals.

Results: The radiographers had shown a positive attitude towards using GS, however none of them used it in daily practice for a various reason such as (GS may obscure region of interest $11.1 \%$, uncooperative patient $16.7 \%$, too busy $13.9 \%$, GS not available $27.8 \%$ and no appropriate size GS $27.8 \%$ ). The investigators had also reviewed 94 abdominal-pelvic radiographs and none was taken with application of GS.
\end{abstract}

Conclusion: Although the radiographers had a positive attitude, none of them had applied GS while taking plain radiographs and/or CT scan in and around the gonads. Updates on their knowledge on gonadal shielding and enforcing every medical imaging technologist to comply with hospital protocols are recommended.

\section{Introduction}

In medical practice, radiation is used extensively for purpose of diagnosis and treatment. Most of the ionizing radiation from medical procedures originates either from $\mathrm{x}$-rays (including computed tomography (CT) and fluoroscopy) or radioactive tracers.

Protective safeguarding of radiosensitive organs like gonads, thyroid during medical imaging has gained ground mainly based on extrapolation of existing data from Japanese survivors of atomic bombings that took place in 1945 [1,2]. The analysis showed direct relationship between the dose and risk of developing any solid cancer. Patient radio sensitivity was heavily dependent on age at the time of exposure, with children at greater risk of developing future radiationinduced cancer than adults [3].

In order to ensure that the patient receives the lowest possible radiation dose during the diagnostic imaging; adjusting the parameters like; the use of correct collimation of the primary beam, selection of appropriate exposure factors and correct radiographic positioning are essential [4]. In addition, protecting the gonads of children is of particular importance during diagnostic imaging of the pelvis lower abdomen or proximal femur, since evidence suggests that X-rays could cause direct damage to the gonad which could result in mutation [5]. Using gonad shielding during diagnostic X-ray procedures is: an effective way of reducing the risk of genetic effects in future generations [6], may be quite effective to lower the dose to the tests $(95 \%)$ than females $(50 \%)$ ovaries $[7,8]$. In clinical practice, omission of gonadal shielding is not rare [9-12]. Inadequate shielding and or omission of gonad shielding may increases the radiation dose of the gonads which leads to harmful effects..Omission and/ or inadequate shielding can be caused by lack of skill and the attitudes of medical radiologic technologist/radiographers towards gonad shielding. The use of gonad shielding relies on the attitudes of medical imaging technologists (MRTs)/radiographers to steadily follow to professional conduct requirements [13-16]. In a retrospective study done on pelvic radiographs it was found that only $23 \%$ of radiographs (out of 355 radiographs) had been performed correct gonad shielding. In the other67\% of radiographs gonad shielding were not used at all. In the remaining $10 \%$ gonad shielding, the shield was applied incorrectly [17]. In the same research from all patients having $x$-ray examination $45 \%$ of them were exposed twice, to unnecessary radiation [17]. In another retrospective study which considers 1,047 radiographs of 111 children under the age of 16 years, the gonadal shields successfully protected the gonads in $466(49.2 \%)$ radiographs, while 270 (28.5\%) of radiographers were completely omitted. The remaining $212(22.3 \%)$ of radiographs the gonad shielding did not protect the gonads exposing them to unnecessary radiation [18]. In a similar study done by Kenny $\mathrm{N}$, Hill J [19] shows Gonad shields had been completely omitted in 137 (40\%) antero-posterior pelvic radiographs performed on the 32 patients at the time of completion of the study. In 100 radiographs

Correspondence to: Dr. SeifeTeferi, Assistance professor of Medical Physics Addis Ababa University College of Health sciences, school of medicine, Department of Radiology; Tel: +25192905456; E-mail: seifeteferi@yahoo.com

Key words: pediatrics, pelvic, shielding, radiographer, attitudes

Received: April 28, 2017; Accepted: May 26, 2017; Published: May 29, 2017 
(29\%) the gonad shields were adequately protecting the gonads, but in 109 radiographs $(31 \%)$ the gonad shields were not protecting the gonads due to incorrect positioning of the shield [19]. The incorrect positioning of the gonad shields was more commonly found in girls than boys (64 vs 45; p less than 0.012), presumably because of the difficulty in determining gonadal position in relation to surface landmarks [19].

Different studies confirm that pelvic radiography of children was commonly performed during $\mathrm{x}$-ray examination. Below the reproductive ages, the gonads were highly sensitive to the effects of radiation. Incorrect or absence of gonad shielding may lead to mutation or direct gonadal damage [16]. Gonad shielding in radiology has become common practice and is recommended by national and international bodiesduring plain film radiography and/or CT of the abdomen, pelvis, lower spine or proximal femora, from the primary radiation beam when it does not interfere with obtaining the required diagnostic information. In Ethiopia, gonad shielding may not be applied in diagnostic radiology department, for the following reason: the nature of the examination, the awareness of patients about the advantages of gonad shielding; the devotion of radiographer to apply the gonad shielding to a patient who will be examined and the absence of gonad shielding material. Even if applied the positioning of gonad shields in children's pelvic X-rays may be less than inadequate, allowing for increased gonad exposure to radiation, covering areas of interest [20]. So, this study is intended to assess the practice of gonad shielding during pelvic radiography in two large public general hospitals in the capital city of Ethiopia, Addis Ababa. The study also tried to investigate the attitude of medical radiologic technologists/radiographers towards application of gonad shielding of pediatric patients during radiographic examination

\section{Materials and methods}

The aim of this work is to investigate the application of gonadal shielding of pediatric patients under 15 years of age undergoing diagnostic X-ray examinations and to evaluate knowledge and practice of gonad shielding of technologists/Radiographers towards gonad shielding. The study utilized a cross-sectional study design. The study was done in two large public general hospitals located in Addis Ababa. These two hospitals were chosen because in addition to well experienced staffs and well-established x-ray departments most pediatric patients are served here as compared to other public hospitals in the city. All 94 pediatric patients radiograph who visited both hospitals' $\mathrm{x}$-ray departments to seek pelvic $\mathrm{x}$-ray and/or abdomen-pelvic CT during the study period of three month (from June 1 to August 30, 2014) were included in the research by convenience. 55 (58.5\%) radiographs were from Black lion and the rest 39(41.5\%) were from Saint Paulo's Hospitals. All X-rays were reviewed by a single person for consistency. All 36 medical imaging technologists/Radiographer's working in these two hospitals were the study population

Data collection was done with the cooperation of departmental staff, which included radiographers, medical radiologic technologists and darkroom technicians. Data collection was accomplished using self-administered questionnaires designed to obtain relevant socio demographic characteristics such as age, level of education, work experience. Daily recordings were compiled by frontline senior radiologists and or residents in the reporting room to assess the application of gonadal shielding in all pediatric X-ray examinations. Information sheets explaining about the objectives of the study and the benefits of the research findings to patients undergoing radiologic investigation in particular was provided to each study subject before submitting the questionnaire. A brief consent form was also submitted to the study participants and those who consented were provided the self-administered questionnaires.

The collected data was anonymous and the investigators did not provide information to the third parties. The collected data cleaned, coded and entered using SPSS version 20 statistical software package and analyzed.

\section{Result}

A total of 36 medical radiologic technologists (MRT)/radiographers were involved in this study. The demographic characteristics of respondents who completed questionnaires are given in Table 1.

The mean age of the respondents was $32+/-10.4$ years (range 20 to 60 years) where 25 of them were female and 11 males. About $80.6 \%$ (29 of 36) of them are MRT (4years education) while 19.4\% (7 of 36) were radiographer (2year education). The mean years of professional experience was 9.4 years with maximum years of above 20 and minimum years of 1 year (Table 1 ).

As shown in Table 2, out of 36 employees; 25 were working at plain radiograph, 7 at procedure unit and 4 at CT scan unit. $72.2 \%$ (26 of 36) of them responded Gonadal shield was available in their unit (16 plain radiographs, 7 at procedure and 3 at CT unit) while the remaining $27.8 \%$ (10 of 36) of respondent were not aware of the existence of GS at their unit. As shown in Table 3, although 100\% (36 of 36) of MRTs/ radiographers agreed on the protective value of GS, none of them were used it for different reason (Table 4). The investigators had reviewed observations on total of 94 pelvic, lower abdomen and lumbosacral radiographs (55 at Saint Paul and 39 at $\mathrm{BLH}$ ) and found out none of the image were taken with application of GS.

\section{Discussion}

For about five decades, medical radiologic technologists/ radiographers worldwide have been taking in the radiography of the pelvis and abdomen. As a result, children may receive several radiographic examinations with unavoidable extra radiation to their gonads from poor positioning and/or complete omission of GS.

Table 1. Demographic characteristics of the respondents

\begin{tabular}{|c|c|c|c|}
\hline \multirow{2}{*}{ Tharacteristic } & & & \\
\hline Age & & Range (20-60yr) & \\
\hline \multirow{2}{*}{ Sex } & Male & 25 & 69.4 \\
\hline \multirow{2}{*}{ Level of education } & Female & 11 & 30.6 \\
\cline { 2 - 4 } & Diploma & 7 & 19.5 \\
\hline \multirow{3}{*}{$\begin{array}{c}\text { Professional year of } \\
\text { experience }\end{array}$} & Degree & 29 & 80.5 \\
\cline { 2 - 4 } & $1-4$ & 17 & 47.2 \\
\cline { 2 - 4 } & $5-9$ & 7 & 19.4 \\
\cline { 2 - 4 } & $10-14$ & 6 & 8.3 \\
\hline
\end{tabular}

Table 2. Availability of gonad shielding at the working unit

\begin{tabular}{|c|c|c|c|c|c|}
\hline \multirow{2}{*}{ Working unit } & \multirow{2}{*}{ Total } & \multicolumn{4}{|c|}{ Availability of gonad shielding } \\
\cline { 3 - 6 } & & Yes & $\%$ & No & $\%$ \\
\hline Plain radiograph & 25 & 16 & $64 \%$ & 9 & $36 \%$ \\
\hline Procedure & 7 & 7 & $100 \%$ & 0 & \\
\hline CT unit & 4 & 3 & $75 \%$ & 1 & $25 \%$ \\
\hline Total & 36 & 26 & & 10 & \\
\hline
\end{tabular}


Table 3. Attitudes on the use of gonad shielding in general radiography

\begin{tabular}{|l|l|l|}
\hline Question & & Frequency \\
\hline \multirow{2}{*}{$\begin{array}{l}\text { 1. Likelihood of gonad shielding } \\
\text { application for examination }\end{array}$} & A. Lower abdomen \& pelvic & $29(80.5 \%)$ \\
\cline { 2 - 3 } & B. Chest radiograph & $6(16.6)$ \\
\hline \multirow{2}{*}{$\begin{array}{l}\text { 3. Self-ponad shielding protocol } \\
\text { available in workplace }\end{array}$} & Importance of gonad shielding & $21(58.3)$ \\
\hline \multirow{2}{*}{$\begin{array}{l}\text { 4. Likelihood of not using gonad } \\
\text { shielding when encountering: }\end{array}$} & A. Yes & $36 / 36(100 \%)$ \\
\hline & B. No & $29(80.6 \%)$ \\
\hline & C. Unaware & $4(11.1 \%)$ \\
\hline & A. May obscure region of interest & $3(8.3)$ \\
\hline & D. Not available & $4(1.1)$ \\
\hline \multirow{2}{*}{$\begin{array}{l}\text { 5. Likelihood of shield availability } \\
\text { affecting usage. }\end{array}$} & $\begin{array}{l}\text { E. No appropriate size } \\
\text { often apply it }\end{array}$ & $6(16.7 \%)$ \\
\hline & B. not available & $5(13.9 \%)$ \\
\hline
\end{tabular}

Table 4. Review of radiographs at two hospitals

\begin{tabular}{|c|c|c|c|c|}
\hline Hospital & Male & Female & No. of image taken & GS applied \\
\hline BLH & 21 & 34 & 55 & 0 \\
\hline St. Paul & 18 & 21 & 39 & 0 \\
\hline Total & 39 & 55 & 94 & None \\
\hline
\end{tabular}

It appears that like some other researches [21-23] the effective use of shielding during examinations of the hip and pelvis in these two hospitals is inadequate. Our result indicated that $100 \%$ of children in two hospitals (Table 4) had radiographs taken with no application of protective GS.

The findings presented in Table 3 demonstrate that MRTs/ radiographers possess appropriate knowledge towards the use of gonad shielding in general radiography. Nearly all MRTs/radiographers $(80.6 \%, 29 / 36)$ were aware of the issue of gonad shielding protocol existence. They all perceived gonad shielding as an important issue overall. Nonetheless, the reasons suggested by the respondents for not using the shielding was not in accordance with the guidelines of ICRP publication 34 [6]. The availability of gonad shielding (Table 2) in their respective departments rarely affects the radiographer's intentions to use it (with $72.2 \%$ thought GS had protective value but did not apply it) (Table 3). Only $11.1 \%$ (10/36) of the radiographers/ medical radiologic technologists were not aware of the availability of gonad shielding in their respective exposure room.

Although the attitude and knowledge of radiographer were good, none of them had applied GS during their practice (Table 4). It was found that level of education and years of professional experience had no significant impact on the application of GS in their day to day practice. (Table 1).

It was well known that the risks of exposure of radiation are greatest with young patients. The highest late effects of exposure to low level of radiation are an increased incidence of cancer in exposed individual. The risk increases in children with number of radiographers performed over life time of individual. NRPB guidance [24] about gonad protection should be implemented in all radiological procedures. This is important in pediatric patients in which they are directly exposed to radiation during the course of pelvic examination.

MRTs/radiographers should all take responsibility for protecting pediatric patients. Proper and regular instructions should be issued to them, to ensure correct use of gonadal shielding. Because of resource limitation the current research focuses only in two Hospitals. Further studies should focus on the reason for the non-compliance of the use of gonadal shields. A truly national audit would be needed to confirm our suspicion that this is indeed a problem across in Ethiopia.

\section{Acknowledgment}

We gratefully thank radiographers, heads and other supportive stuffs working in x-ray departments of both hospitals Black-lion and saint Paulo's, for their strong and active participation in filling the records for this research in spite of their routine work load in these busy $\mathrm{x}$-ray departments.

\section{References}

1. Pierce DA, Preston DL (2000) Radiation-related cancer risks at low doses among atomic bomb survivors. Radiat Res 154: 178-186. [Crossref]

2. Preston DL, Ron E, Tokuoka S, Funamoto S, Nishi N, et al. (2007) Solid cancer incidence in atomic bomb survivors: 1958-1998. Radiat Res 168: 1-64. [Crossref]

3. Cook JV, Kyriou JC, Pettet A, Fitzgerald MC, Shah K, et al. (2001) Key factors in the optimization of paediatric X-ray practice. Br J Radiol 74: 1032-1040. [Crossref]

4. McCollough CH, Primak AN, Braun N, Kofler J, Yu L, et al. (2009) Strategies for reducing radiation dose in CT. Radiol Clin North Am 47: 27-40. [Crossref]

5. Sikand M, Stinchcombe S, Livesley PJ (2003) Study on the use of gonadal protection shields during paediatric pelvic X-rays. Ann R Coll Surg Engl 85: 422-425. [Crossref]

6. Bardo DM, Black M, Schenk K, Zaritzky MF (2009) Location of the ovaries in girls from newborn to 18 years of age: reconsidering ovarian shielding. Pediatr Radiol 39:253-259 [Crossref]

7. FDA (2013) 21 CFR 1000.50 Recommendation for the use of specific area gonad shielding on patients during medical diagnostic x-ray procedures. Available via http:// cfr.vlex.com/vid/1000-recommendation-gonad-shielding-patients-ray-19716085, 1976. Accessed

8. International Commission on Radiological Protection Protection of the patient in diagnostic radiology (ICRP publication 34). Ann. ICRP 1982;9 (2-3), Pergamon, Oxford

9. Doolan A, Brennan PC, Rainford LA, Healy J (2004) Gonad protection for the anteroposterior projection of the pelvis in diagnostic radiography in Dublin hospitals. Radiography 10: 15-21.

10. [No authors listed] (1982) Protection of the patient in diagnostic radiology. A report of Committee 3 of the International Commission on Radiological Protection. Ann ICRP 9: 1-82. [Crossref]

11. Frank ED, Long BW, Smith BJ (2007) Merrill's atlas of radiographic positioning \& procedures, 11th edition. St. Louis: Mosby; pp33-35.

12. Sherer MA, Visconti PJ, Ritenour ER (2011) Radiation protection in medica radiography, 6th edition. Missouri: Mosby, Inc. pp248-52.

13. Australian Institute of Radiography (AIR) (2007) Guidelines for professional conduct for radiographers, radiation therapists and sonographers. Melbourne: AIR.

14. Cook JV (2001) Radiation protection and quality assurance in paediatric radiology Imaging 13: 229-38.

15. MacKay M, Hancy, C, Crowe A, D'Rozario, R, Ng CKC (2012) Attitudes of Medical Imaging Technologists on Use of Gonad Shielding in General Radiography.The Radiographer 59: 35-39.

16. Almén A, Mattsson S (1995) The radiation dose to children from X-ray examinations of the pelvis and the urinary tract. Br J Radiol 68: 604-613. [Crossref]

17. Sikand M, Stinchcombe S, Livesley PJ (2003) Study on the use of gonadal protection shields during paediatric pelvic X-rays. Ann R Coll Surg Engl 85: 422-425. [Crossref]

18. Gul A, Zafar M, Maffulli N (2005) Gonadal shields in pelvic radiographs in pediatric patients. Bull Hosp Jt Dis 63: 13-14. [Crossref]

19. Kenny N, Hill J (1992) Gonad protection in young orthopaedic patients. BMJ 304 1411-1413. [Crossref]

20. Wainwright AM (2000) Shielding reproductive organs of orthopaedic patients during pelvic radiography. Ann R Coll Surg Engl 82: 318-321 
Teferi S (2017) Preliminary study on the practice of gonad shielding during pelvic radiography

21. Kenny N, Hill J (1992) Gonad protection in young orthopaedic patients. BMJ 304: 1411-1413. [Crossref]

22. Sikand M, Stinchcombe S, Livesley PJ (2003) Study on the use of gonadal protection shields during paediatric pelvic X-rays. Ann R Coll Surg Engl 85: 422-425
23. Gul A, Zafar M, Maffulli N (2005) Gonadal shields in pelvic radiographs in pediatric patients. Bull Hosp Jt Dis 63: 13-14. [Crossref]

24. National Radiological Protection Board. National protocol for patient dose measurements in diagnostic radiology. Report of the Working Party of the Institute of Physical Science in Medicine (Chilton, Didcot, UK: NRPB) (1992).

Copyright: (C2017 Teferi S. This is an open-access article distributed under the terms of the Creative Commons Attribution License, which permits unrestricted use, distribution, and reproduction in any medium, provided the original author and source are credited. 